\title{
Characterization and Doping Effect of Cu-Doped ZnO
}

\section{Films}

\author{
Khin Khin Kyaw ${ }^{1}$ and Hla Toe ${ }^{2}$ \\ 1. Department of Physics, University of Yangon, Kamayut 11041, Myanmar \\ 2. Department of Physics, Panglong University, Panlong 06114, Myanmar
}

\begin{abstract}
Cu}$ (copper)-doped $\mathrm{ZnO}$ (zinc oxide) was synthesized using $\mathrm{Cu}\left(\mathrm{NO}_{3}\right)_{2} \cdot 3 \mathrm{H}_{2} \mathrm{O}$ (copper (II) nitrate) and $\mathrm{Zn}\left(\mathrm{NO}_{3}\right)_{2} \cdot 6 \mathrm{H}_{2} \mathrm{O}(\mathrm{zinc}$ nitrate) by chemical co-precipitation method. The weight percentages of dopant in solution were $\mathrm{Cu}(2,3$, and $5 \mathrm{wt} \%)$. Cu-doped $\mathrm{ZnO}$ thin films were prepared on $\mathrm{p}-\mathrm{Si}$ (100) substrate by screen printing method. Cu-doped $\mathrm{ZnO} / \mathrm{Si}$ films were annealed at different temperatures from 300 to $700{ }^{\circ} \mathrm{C}$. In this study, Cu-doped $\mathrm{ZnO}$ structures were prepared by a simple precipitation technique, and characterized by various techniques such as XRD (X-ray diffraction) and SEM (scanning electron microscope). The electrical properties of $\mathrm{Cu}$-doped $\mathrm{ZnO} / \mathrm{Si}$ were measured. It has found that $\mathrm{Cu}$-doped $\mathrm{ZnO} / \mathrm{Si}$ films can be used as optoelectronic devices.
\end{abstract}

Key words: Copper doped zinc oxide, silicon, optoelectronic device, co-precipitation method.

\section{Introduction}

$\mathrm{ZnO}$ (zinc oxide) is an unexpensive, n-types semiconductor with a wide band gap having optical transparency in the visible range. It crystallizes in a hexagonal wurtzite structure with the following lattice parameters $c=5.205 \AA$, $a=3.249 \AA$ [1]. The n-type semiconductor behavior is due to the ionization of excess zinc atoms in interstitial positions and the oxygen vacancies. Surface defects play an important role in the photocatalytic activities of metal oxides as they increase the number of the active sites [2]. For this reason it is interesting to study the effect of $\mathrm{ZnO}$ doped by transition metals on its photocatalytic properties. Data are reported in the current literature about the influence of copper $(\mathrm{Cu})$ dopant in $\mathrm{ZnO}$ powder and thin films on the photocatalytic behavior. Various techniques for preparation of $\mathrm{ZnO}$ have been applied: sol-gel method, the co-precipitation method etc. [3].

In this research work, the crystalline structure of the as-prepared $\mathrm{Cu}-\mathrm{ZnO}$ films was characterized by XRD (X-ray diffraction). The surface microstructure was

Corresponding author: Hla Toe, $\mathrm{PhD}$, professor, research field: physics. obtained by SEM (scanning electron microscope). The UV (ultraviolet)-visible absorption of the samples was recorded using UV-Vis spectrometer in the wavelength range of $190-1,100 \mathrm{~nm}$. $\mathrm{Cu}-\mathrm{ZnO} / \mathrm{Si}$ thin films were done by co-precipitation method and screen printing method [4]. We present the temperature dependent characterization and photovoltaic property of the samples to investigate the mechanism of photovoltaic effect. $I-V \quad$ (current-voltage) measurements are carried out to investigate the electrical properties of $\mathrm{Cu}-\mathrm{ZnO} / \mathrm{Si}$ heterojunction. For application in optoelectronic devices, the optimum film diffusion temperature should be chosen for the best devices performance.

\section{Experimental Details}

\subsection{Synthesis of Undoped $\mathrm{ZnO}$ and Cu-Doped $\mathrm{ZnO}$}

The synthesis of undoped and $\mathrm{Cu}$-doped $\mathrm{ZnO}$ samples has been prepared by co-precipitation method. Pure $\mathrm{Zn}\left(\mathrm{NO}_{3}\right)_{2} \cdot 6 \mathrm{H}_{2} \mathrm{O}$ (zinc nitrate) of analytical grade, $\mathrm{Cu}\left(\mathrm{NO}_{3}\right)_{2} \cdot 3 \mathrm{H}_{2} \mathrm{O}$ (copper II nitrate) of the various ratios (2, 3 and $5 \mathrm{wt} \%$ ), ammonia and $\mathrm{D} / \mathrm{I}$ (distill water) were used as reagent materials. In a typical experiment, $\mathrm{Zn}\left(\mathrm{NO}_{3}\right)_{2}$ and $\mathrm{Cu}\left(\mathrm{NO}_{3}\right)_{2}$ were dissolved 
D/I water. Ammonia was added to solvent (drop by drop). The solvent were stirring on hot plate stirring. After $2 \mathrm{hr}$ later, the white precipitation was deposited on the bottom of the flask. The solvent stirring process was shown for precipitation process in Fig. 1. The precipitate samples were centrifuged shown in Fig. 2a. The white solid was collected and washed several times with $\mathrm{D} / \mathrm{I}$, ethanol and dried in air with filter paper shown in Fig. 2b. After heat treated process $\mathrm{Cu}$-doped $\mathrm{ZnO}$ powder was achieved shown in Figs. $3 \mathrm{a}$ and $3 \mathrm{~b}$. Slices of cleaned p-typed $\operatorname{Si}(100)$ were used as substrates for $\mathrm{Cu}$-doped $\mathrm{ZnO}$ deposited on $\mathrm{Si}$ film. After the synthesis process, the $\mathrm{Si}$ (silicon) substrates were sequentially cleaned with an acetone, $\mathrm{D} / \mathrm{I}$ water and $\mathrm{HCl}$ into the beaker and Si wafer dipped in the solution for $30 \mathrm{~min}$. Cleaning work was shown in Fig. 4b. Etching solvent was used to remove organic contaminants and grease. After this step, substrates were rinsed with deionized water for $30 \mathrm{~min}$. The final samples were heated for $3 \mathrm{~h}$ at $100^{\circ} \mathrm{C}$ and calcinated at $450^{\circ} \mathrm{C}$ for $1 \mathrm{~h}$ in furnace, this process is shown in Fig. 5 b.

In this work, the best ratio of $\mathrm{Cu}$-doped $\mathrm{ZnO}$ powder was placed into the beaker and mixed with 2-methoxythanol (1 mL) and PPG (propylene glycol) and stirred homogeneously for $2 \mathrm{~h}$. After that $\mathrm{Cu}$-doped $\mathrm{ZnO}$ solvent was obtained to use for deposition on Si substrate. This process was shown in Fig. 4a. The $\mathrm{Cu}$-doped $\mathrm{ZnO}$ solvent was deposited on clean Si substrate by screen printing method; it was shown in Fig. 5a. Then, finally the $\mathrm{Cu}$-doped $\mathrm{ZnO}$ deposited on Si samples was placed into the furnace

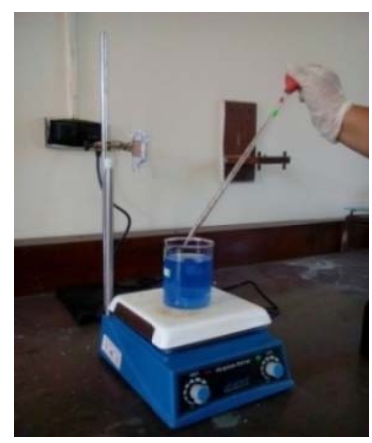

Fig. 1 Stirring the solvent.

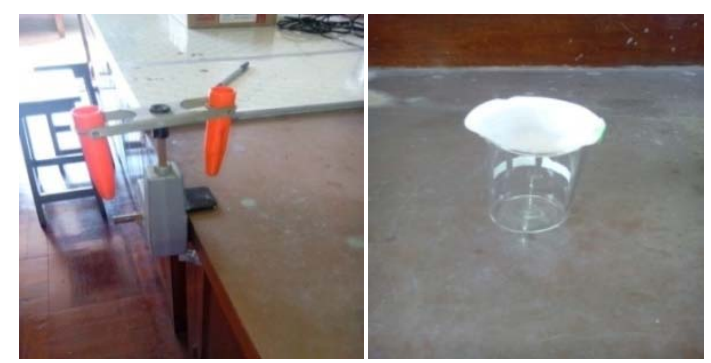

Fig. 2 (a) Centrifuge; (b) dried in air.
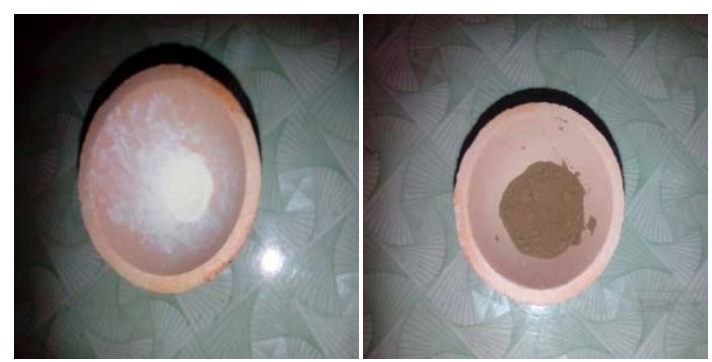

Fig. 3 (a) Pure $\mathrm{ZnO}$ powder; (b) Cu-doped ZnO.
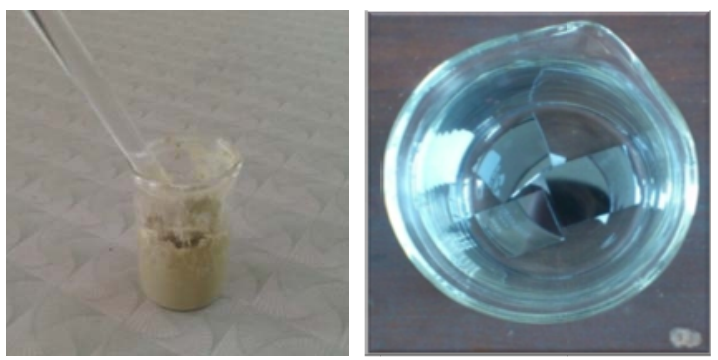

Fig. 4 (a) $\mathrm{Cu}-\mathrm{ZnO}$ solvent; (b) Si cleaning.
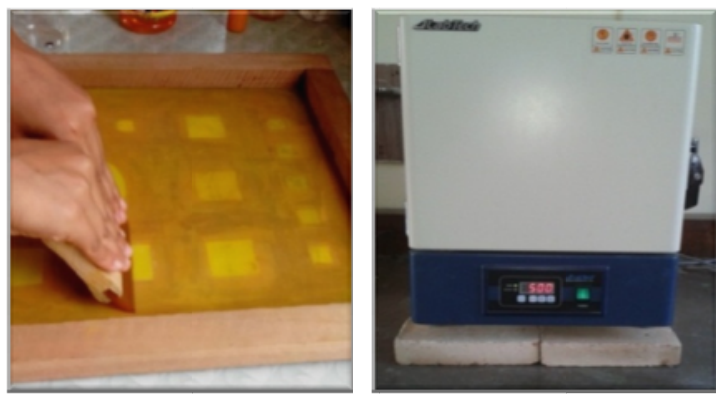

Fig. 5 (a) Screen printing process; (b) thermal diffusion process.

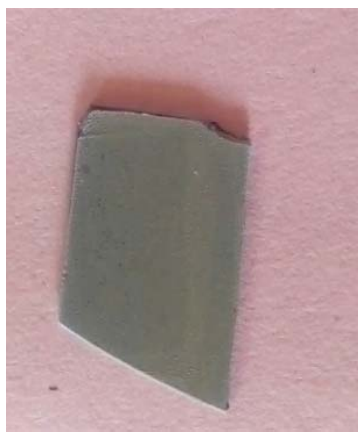

Fig. $6 \mathrm{Cu}-\mathrm{ZnO} / \mathrm{Si}$ film $600{ }^{\circ} \mathrm{C}$. 
and annealed to samples at different temperatures from 300 to $700{ }^{\circ} \mathrm{C}$ for $30 \mathrm{~min}$ to each sample. Fig. 6 shows $\mathrm{Cu}$-doped $\mathrm{ZnO}$ deposited on $\mathrm{Si}$ film at deposition temperature $600{ }^{\circ} \mathrm{C}$. Experimental procedure of this research was clearly step by step shown in Fig. 7.

The samples were characterized by XRD using multiflex-2 kW type X-ray diffractometer with $\mathrm{Cu}-\mathrm{K} \alpha$ radiation. The particle morphologies of the $\mathrm{ZnO}$ powder and $\mathrm{Cu}-\mathrm{ZnO}$ powder were observed by SEM. $I-V$ characteristic of each sample was measured by LUX meter, Fluke-45 dual display multimeter and other supporting equipments.

\subsection{Structural Properties of $\mathrm{ZnO}$ and $\mathrm{Cu}-\mathrm{ZnO} / \mathrm{Si}$ Device by $X R D$}

The XRD spectra show the syntheses $\mathrm{ZnO}$ and $\mathrm{Cu}-\mathrm{ZnO}$ were presented. The characterization of
$\mathrm{Cu}-\mathrm{ZnO} / \mathrm{Si}$ with respect to phase identification, crystal structure was determined by XRD with $\mathrm{Cu}-\mathrm{K} \alpha$ radiation. The XRD analysis of synthesized $\mathrm{ZnO}$ and $\mathrm{Cu}$-doped $\mathrm{ZnO}$ deposited on $\mathrm{Si}$ at $600{ }^{\circ} \mathrm{C}$ was shown in Figs. 8 and 9 respectively. The XRD analysis of $\mathrm{Cu}$-doped $\mathrm{ZnO}$ deposited on $\mathrm{Si}$ samples at different deposition temperatures was shown in Fig. 10. The crystallite size is calculated from peak broadening using Debye-Scherer formula $\left(D_{\mathrm{hkl}}=\frac{0.899 \lambda}{B \cos \theta}\right)$. The average crystallite size of all samples was shown in Tables 1 and 2. XRD peaks (101) plane was shifted slightly depending on the deposition temperature. Fig. 8 shows the $\mathrm{ZnO}$, similar to (Joint Committee on Powder Diffraction Standards) card No. 80-0075, formed in crystalline state. The crystallite size is calculated from dominant peak broadening of (101) plane.

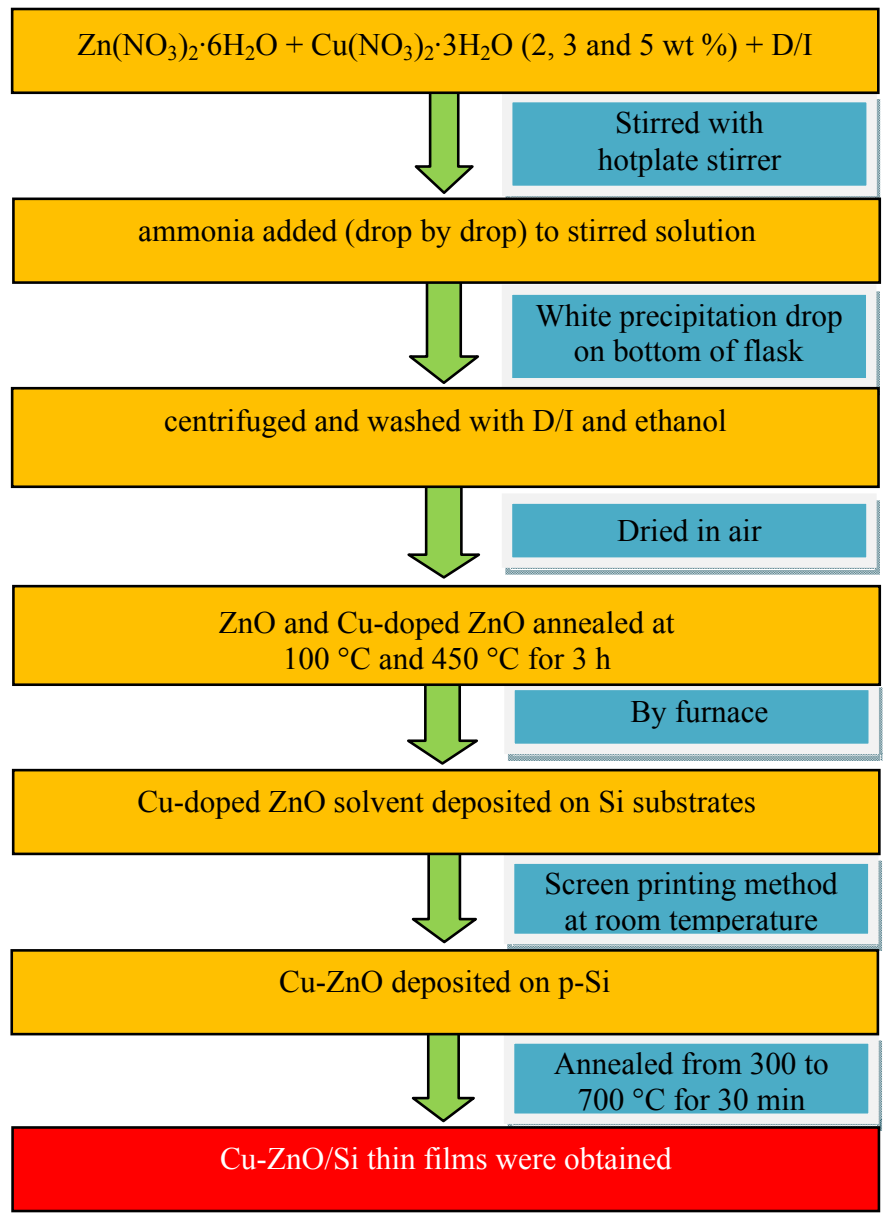

Fig. 7 Block diagram of synthesis of $\mathrm{ZnO}$ and $\mathrm{Cu}$-doped $\mathrm{ZnO} / \mathrm{Si}$ thin films. 


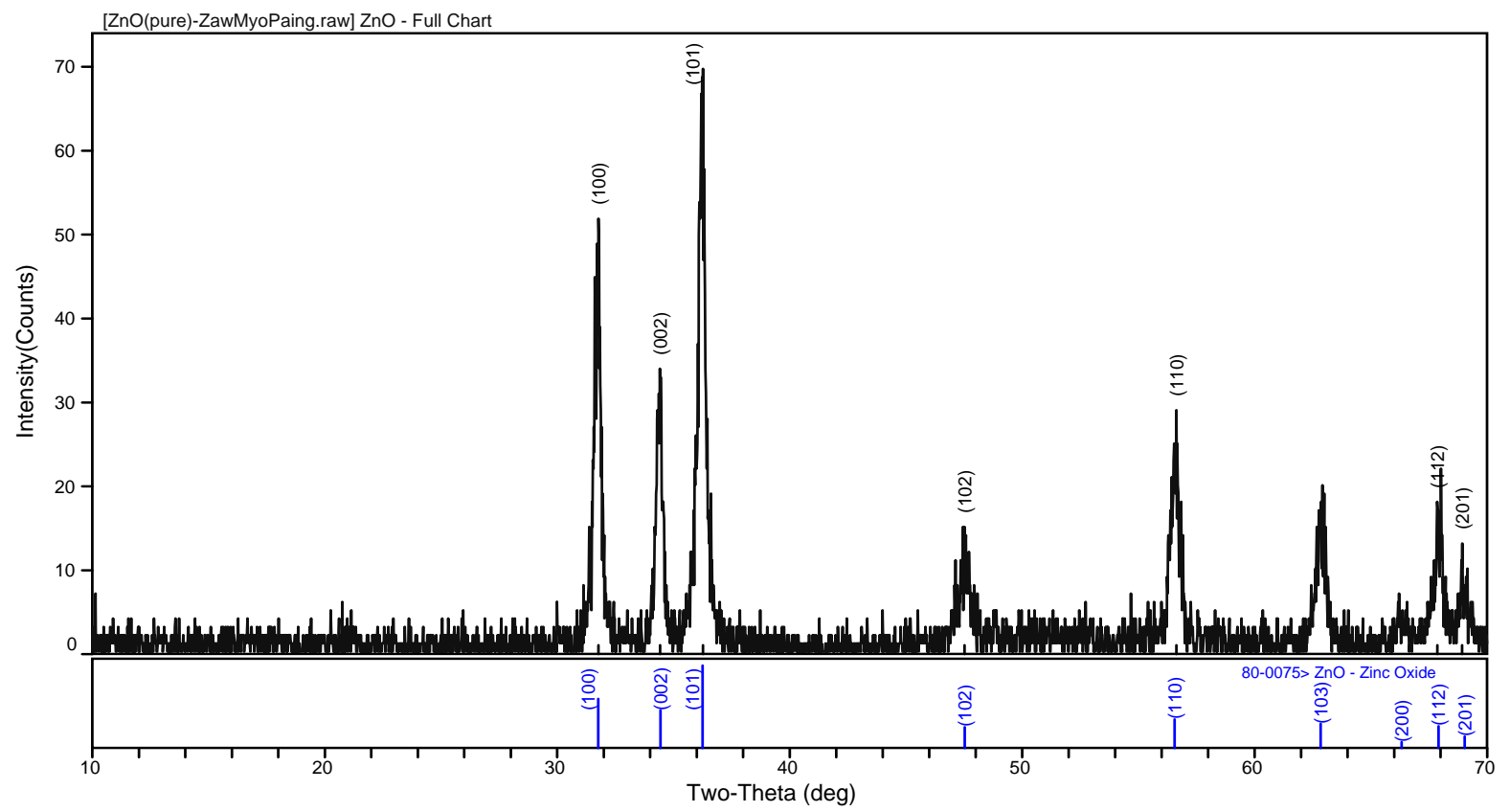

Fig. 8 The XRD analysis of synthesis of $\mathrm{ZnO}$ powder.

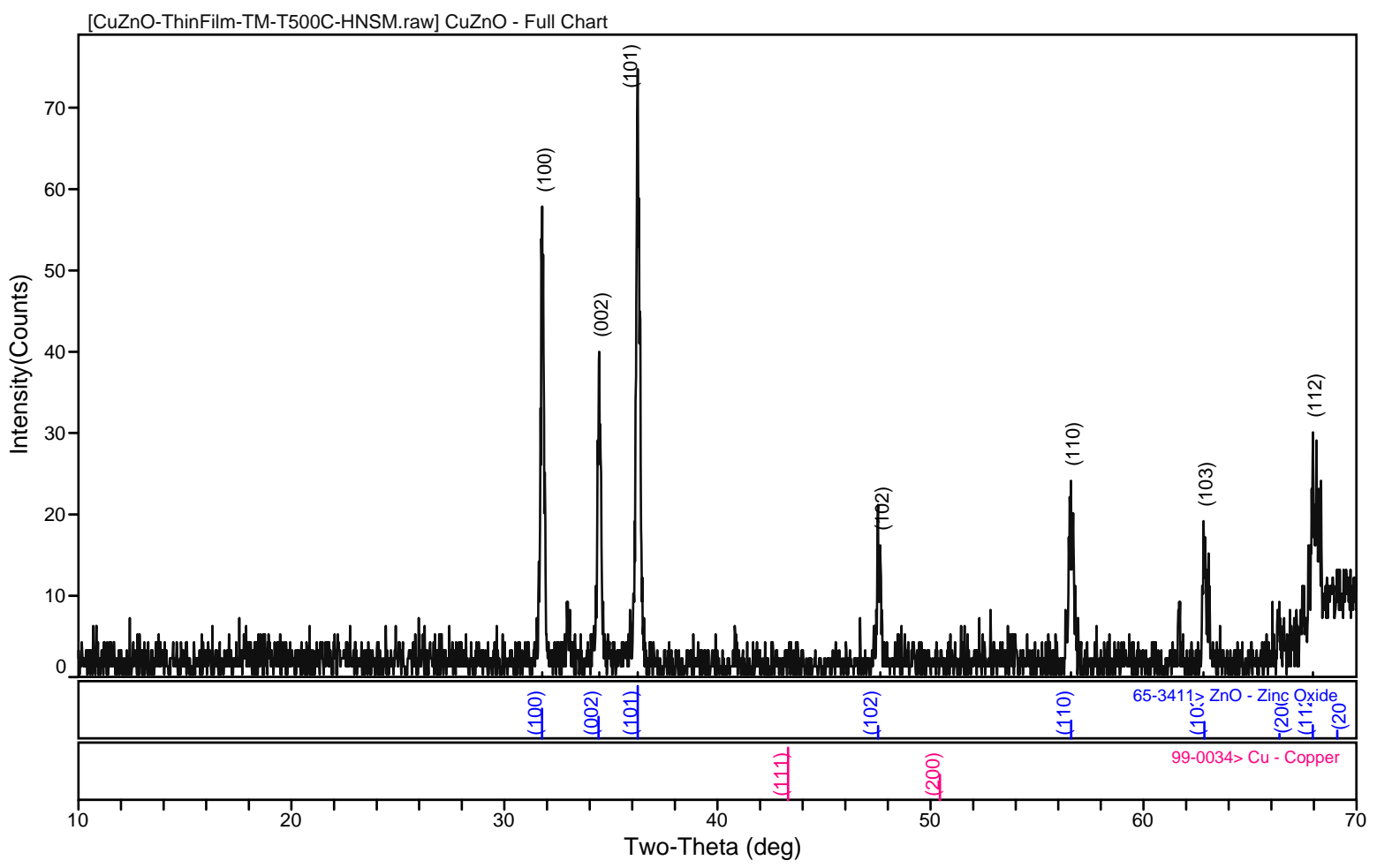

Fig. 9 The XRD of $\mathrm{Cu}-\mathrm{ZnO} / \mathrm{Si}$ thin film at $600^{\circ} \mathrm{C}$. 


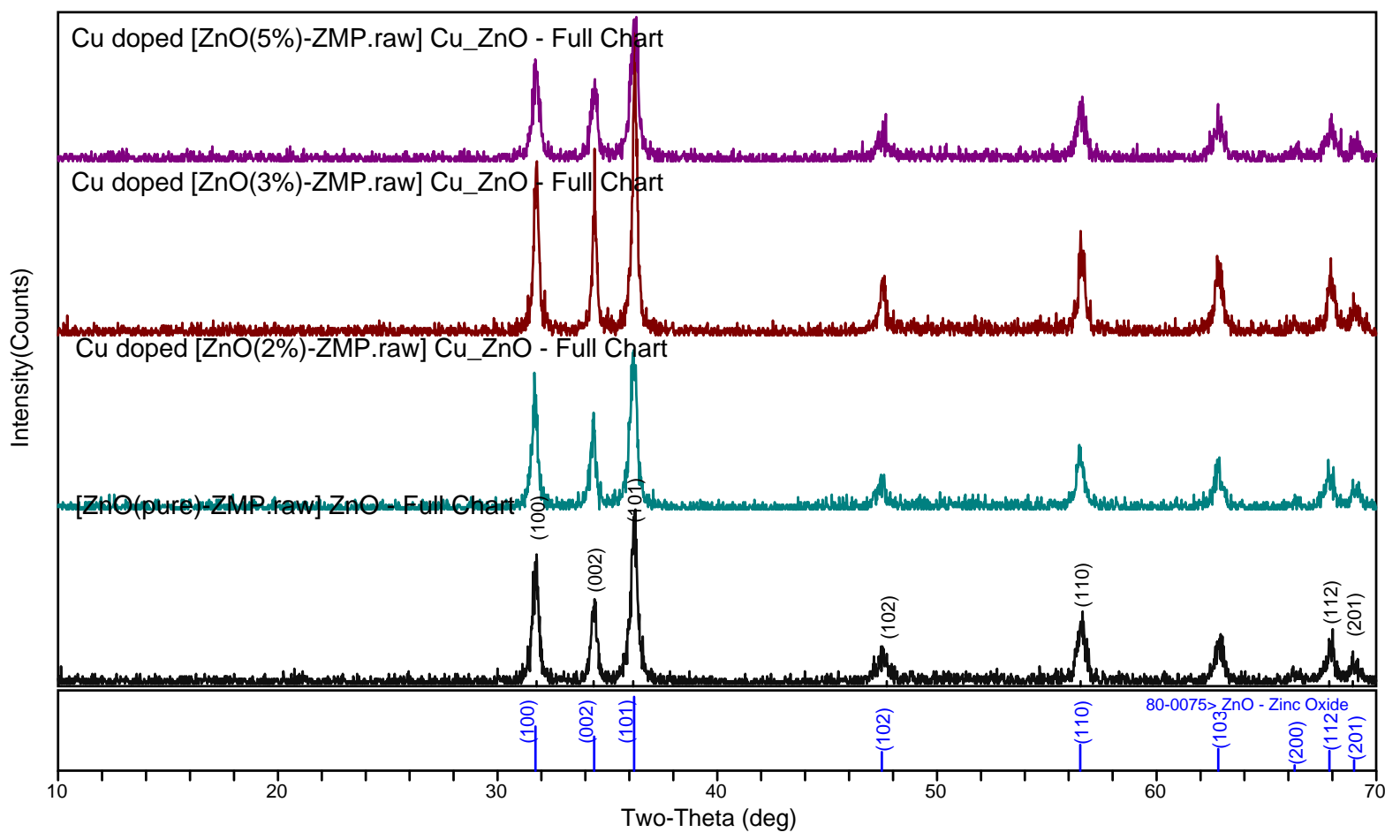

Fig. 10 Comparison of the XRD diffraction analysis of undoped and doped powder.

Table 1 Crystallite size calculation of undoped $\mathrm{ZnO}$ powder and $\mathrm{Cu}$-doped $\mathrm{ZnO}$ powder.

\begin{tabular}{llllllll}
\hline $\begin{array}{l}\text { Samples } \\
\text { (different weight ratios) }\end{array}$ & $2 \theta\left({ }^{\circ}\right)$ & hkl plane & FWHM & $\begin{array}{l}\text { Lattice } \\
\text { constant }(a)\end{array}$ & c/a & $\begin{array}{l}\text { Crystal } \\
\text { structure }\end{array}$ & $\begin{array}{l}\text { Crystallite } \\
\text { size }(\mathrm{nm})\end{array}$ \\
\hline Undoped synthesis ZnO & 36.278 & $(101)$ & 0.340 & 3.2484 & 1.604 & Hexagonal & 24.55 \\
Cu-ZnO synthesis powder ratio (2 wt \%) & 36.318 & $(101)$ & 0.630 & 3.2511 & 1.602 & Hexagonal & 27.833 \\
Cu-ZnO synthesis powder ratio (3 wt \%) & 36.259 & $(101)$ & 0.227 & 3.2480 & 1.605 & Hexagonal 36.783 \\
Cu-ZnO synthesis powder ratio (5 wt \%) & 36.281 & $(101)$ & 0.370 & 3.2538 & 1.601 & Hexagonal 22.568 \\
\hline
\end{tabular}

FWHM: full width at half maximum.

Table 2 Crystallite size calculation of $\mathrm{Cu}$-doped $\mathrm{ZnO} / \mathrm{Si}$ thin films (3 wt \%).

\begin{tabular}{llllllll}
\hline $\begin{array}{l}\text { Samples } \\
\text { (different heat treatment temperature) }\end{array}$ & $2 \theta\left(^{\circ}\right)$ & $\mathrm{hkl}$ & $\mathrm{FWHM}\left({ }^{\circ}\right)$ & $\begin{array}{l}\text { Lattice } \\
\text { constant }(a)\end{array}$ & $c / a$ & $\begin{array}{l}\text { Crystal } \\
\text { structure }\end{array}$ & $\begin{array}{l}\text { Crystallite } \\
\text { size }(\mathrm{nm})\end{array}$ \\
\hline 300 & 36.279 & $(101)$ & 0.202 & 3.2471 & 1.604 & Hexagonal & 41.34 \\
400 & 36.319 & $(101)$ & 0.208 & 3.2453 & 1.602 & Hexagonal & 40.15 \\
500 & 36.226 & $(101)$ & 0.172 & 3.2515 & 1.600 & Hexagonal 48.54 \\
600 & 36.259 & $(101)$ & 0.198 & 3.2489 & 1.601 & Hexagonal 42.17 \\
700 & 36.260 & $(101)$ & 0.181 & 3.2495 & 1.606 & Hexagonal 46.13 \\
\hline
\end{tabular}

Table 3 The energy band-gap of $\mathrm{ZnO}$ particles and $\mathrm{Cu}$-doped $\mathrm{ZnO}$ particles.

\begin{tabular}{lll}
\hline Samples & $\lambda(\mathrm{nm})$ & $E_{g}(\mathrm{eV})$ \\
\hline Pure $\mathrm{ZnO}$ & 348 & 3.54 \\
2 wt \% Cu-doped $\mathrm{ZnO}$ & 352 & 3.50 \\
3 wt \% Cu-doped $\mathrm{ZnO}$ & 364 & 3.39 \\
5 wt \% Cu-doped $\mathrm{ZnO}$ & 349 & 3.53 \\
\hline
\end{tabular}


Analyses of XRD data for different peaks of $\mathrm{ZnO}$ corresponding to planes (100), (002), (101), (102), (110), (103), (200), (112) and (201) of hexagonal structure have been identified. Major diffraction peaks of $\mathrm{ZnO}$ exhibited a hexagonal structure with preferred grain orientations along (100), (002) and (101) plane, they were shown in Fig. 9. All of the peaks are well matched with the $\mathrm{ZnO}$, which could be indexed as the hexagonal wurtzite structure of $\mathrm{ZnO}$. You can see in comparison of Figs. 8 and 9.

The peaks of XRD spectrum correspond to those of synthesis $\mathrm{ZnO}$ and three different doping ratios of $\mathrm{Cu}-\mathrm{ZnO}$ patterns from the JCPDS data having hexagonal wurtzite structure of the bulk with $c / a$ ratio are 1.604 for undoped synthesis $\mathrm{ZnO}$ and 1.602, 1.605 and 1.601 for $\mathrm{Cu}$-doped $\mathrm{ZnO}$ powder at different doping ratios $(2,3,5 \mathrm{wt} \%)$. These data are mentioned in column 6 of Tables 1 and 2. The peaks of XRD spectrum correspond to those of the synthesis for $\mathrm{Cu}$-doped $\mathrm{ZnO} / \mathrm{Si}$ (3 wt \%) patterns from the JCPDS data having hexagonal wurtzite structure of the bulk with $c / a$ ratios of $1.604,1.602,1.600,1.601$, and 1.606 for different diffusion temperatures from 300 to $700{ }^{\circ} \mathrm{C}$ respectively. Comparison of these analysis data was shown in Table 3 column 6.

Three doping ratios of $\mathrm{Cu}$-doped $\mathrm{ZnO}$ were $2 \theta$ shifted from undoped $\mathrm{ZnO}$ and (3 wt \%) ratio was narrower than other ratio samples. They are clearly shown in column 2 of Tables 1 and 2. Degree of $2 \theta$ of (5 wt \%) sample is nearly same as pure $\mathrm{ZnO}$, it is denoted that $\mathrm{Cu}$ was nearly completely doped into $\mathrm{ZnO}$. But some $\mathrm{Cu}$ ions are left by the (111) and (200) peak. You can see in Fig. 9. It's means that $\mathrm{Cu}$ ions were not completely doped into $\mathrm{ZnO}$.

Crystal structure of $\mathrm{Cu}$ is cubic and $\mathrm{ZnO}$ is hexagonal. In the XRD result, all synthesized $\mathrm{Cu}-\mathrm{ZnO}$ samples were hexagonal structure, so $\mathrm{Cu}$ was doped into $\mathrm{ZnO}$ because synthesized pure $\mathrm{ZnO}$ was also hexagonal structure.

\subsection{SEM Analysis of Cu-Doped ZnO/Si Device}

Typical SEM images for synthesis of $\mathrm{ZnO}$ and
$\mathrm{Cu}-\mathrm{ZnO}$ were shown in Figs. 11a-11d. The size of $\mathrm{ZnO}$ grains is $0.25 \mu \mathrm{m}$. These SEM images show different morphology of surface grain size, which depend on different $\mathrm{Cu}$ doping ratios 2, 3, and $5 \mathrm{wt} \%$. These images were shown in Figs. 11a-11d. These particles are uniform with size chain agglomeration and the average width and length of particles are 0.20 to $0.75 \mu \mathrm{m}$. According to our experimental result, the SEM images of doped samples, no significant change of their hexagonal structure morphology was observed. These data were shown in Table 3. Grain size depends on the doping ratio; increasing the ratio produces the larger grain size. SEM images of all samples clearly show hexagonal structure and it is coincidence of synthesis $\mathrm{ZnO}$ structure. Hexagonal structure patterns were clearly shown in Fig. 11c.

\subsection{UV-Analysis of $\mathrm{ZnO}$ and $\mathrm{Cu}-\mathrm{ZnO}$}

The measurement of the bandgap of materials is important in the semiconductor, nonmaterial and solar industries. The term "bandgap" refers to the energy difference between the top of the valence band to the bottom of the conduction band. The electrons are able to jump from one band to another. In order for an electron to jump from a valence band to a conduction band, it requires a specific minimum amount of energy for the transition, the bandgap energy [7].

The UV-vis DRS (diffuse reflectance spectra) of the synthesized $\mathrm{ZnO}$ and $\mathrm{Cu}-\mathrm{ZnO}$ and $\mathrm{UV}$ spetra of $\mathrm{Cu}$-doped $\mathrm{ZnO}$ particles are shown in Figs. 12 and 13 respectively. The spectrum reveals characteristic of absorption peak of $\mathrm{ZnO}$ at wavelength of $348 \mathrm{~nm}$, which can be assigned to the intrinsic band-gap absorption of $\mathrm{ZnO}$ due to the electron transition from the valence band to the conduction band. The data get from UV graph as shown in Fig. 12. From the absorption peak, the optical energy band gap has been calculated using the formula:

$$
E g=h v=\frac{h c}{\lambda}
$$




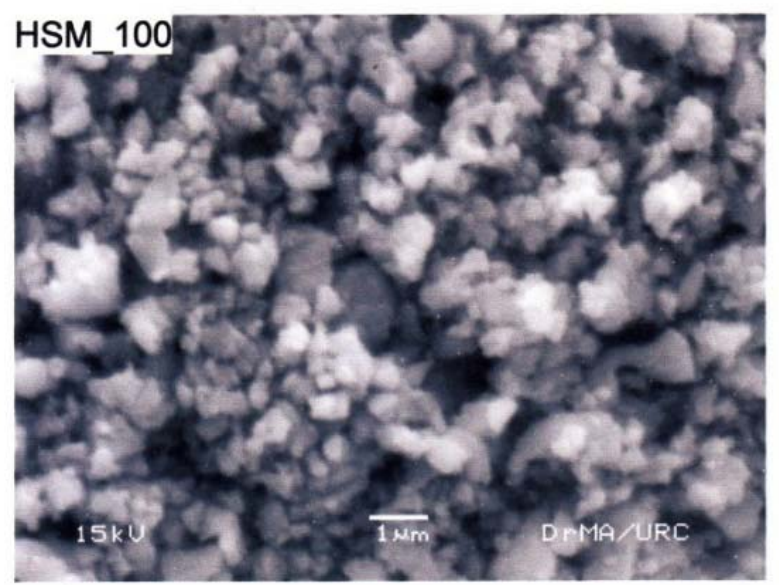

(a)

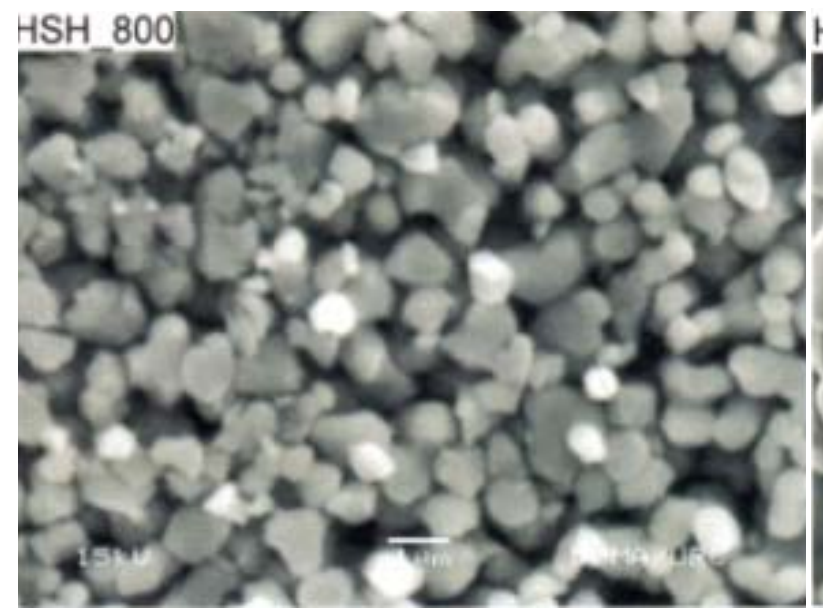

(c)

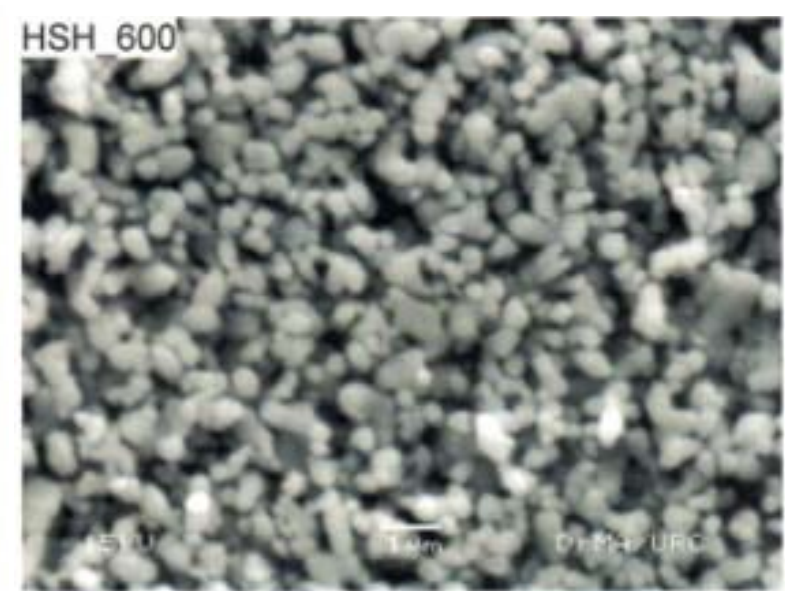

(b)

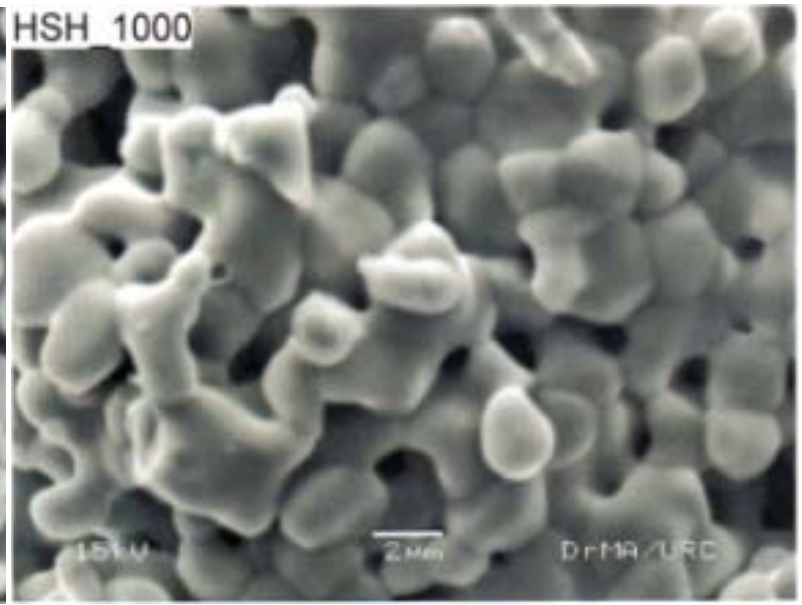

(d)

Fig. 11 (a) Synthesis of pure $\mathrm{ZnO}$ powder; (b) synthesis of $\mathrm{Cu}-\mathrm{ZnO}$ powder (2\%); (c) synthesis of Cu-ZnO powder (3\%); (d) synthesis of $\mathrm{Cu}-\mathrm{ZnO}$ powder (5\%).

where $h=$ plank's constant and $E g=$ energy band gap of the semiconducting particle in the optical spectra. The bandgap of $\mathrm{Cu}$-doped $\mathrm{ZnO}$ was reduced more than undoped $\mathrm{ZnO}$ from $3.54 \mathrm{eV}$ to $3.39 \mathrm{eV}$ (3 wt \% $\mathrm{Cu}$-doped $\mathrm{ZnO}$ ). The bandgap of undoped $\mathrm{ZnO}$ and $\mathrm{Cu}$-doped $\mathrm{ZnO}$ could be determined by finding the wavelength turning edge of the UV-vis absorption peak. These data were shown in Figs. 12 and 13.

In this case, $\mathrm{Cu}^{2+}$ ions replaced $\mathrm{Zn}^{2+}$ ions and formed $\mathrm{CuO}$ in the $\mathrm{ZnO}$. The $\mathrm{CuO}$ has a smaller bandgap $(1.35 \mathrm{eV})$ as compared to $\mathrm{ZnO}(3.37 \mathrm{eV})$.

Thus, when the $\mathrm{CuO}$ was introduced into the $\mathrm{ZnO}$ lattice, the intrinsic bandgap of $\mathrm{ZnO}$ became narrower.

\section{$2.5 \mathrm{I}-\mathrm{V}$ Characteristic Measurement of $\mathrm{Cu}-\mathrm{ZnO} / \mathrm{Si}$} Thin Film

To determine the photovoltaic characterization of the $\mathrm{Cu}-\mathrm{ZnO} / \mathrm{Si}$ film, the $I-V$ characteristics of illumination conditions was studied as shown in Fig. 14. Under the illumination condition, the reverse current strongly increases with illumination intensity of 1,000 LUX. I- $V$ measurement of $\mathrm{Cu}-\mathrm{ZnO} / \mathrm{Si}$ device gives a maximum open circuit voltage $V_{\mathrm{oc}}$ and short-circuits current $I_{\mathrm{sc}}$ as shown in Tables 4 and 5.

$$
\eta=\frac{P_{\text {out }}}{P_{\text {in }}} \Rightarrow \eta=\frac{P_{M A X}}{P_{\text {in }}}
$$




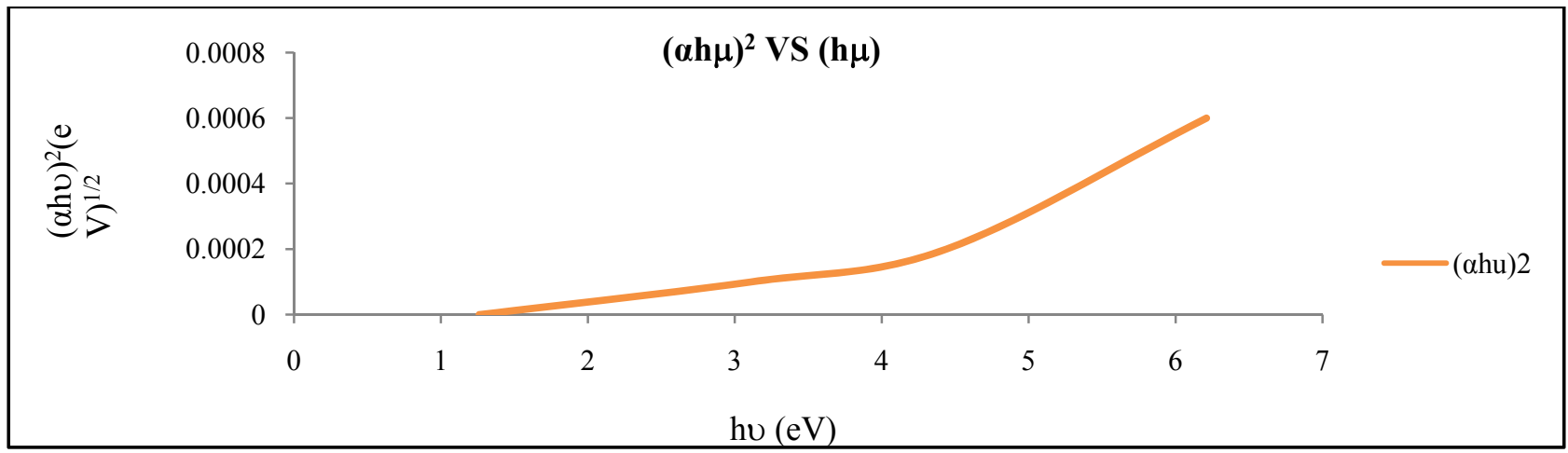

Fig. 12 The plot for band-gap energy $\left(E_{\mathrm{bg}}\right)$ of $\mathrm{ZnO}$.

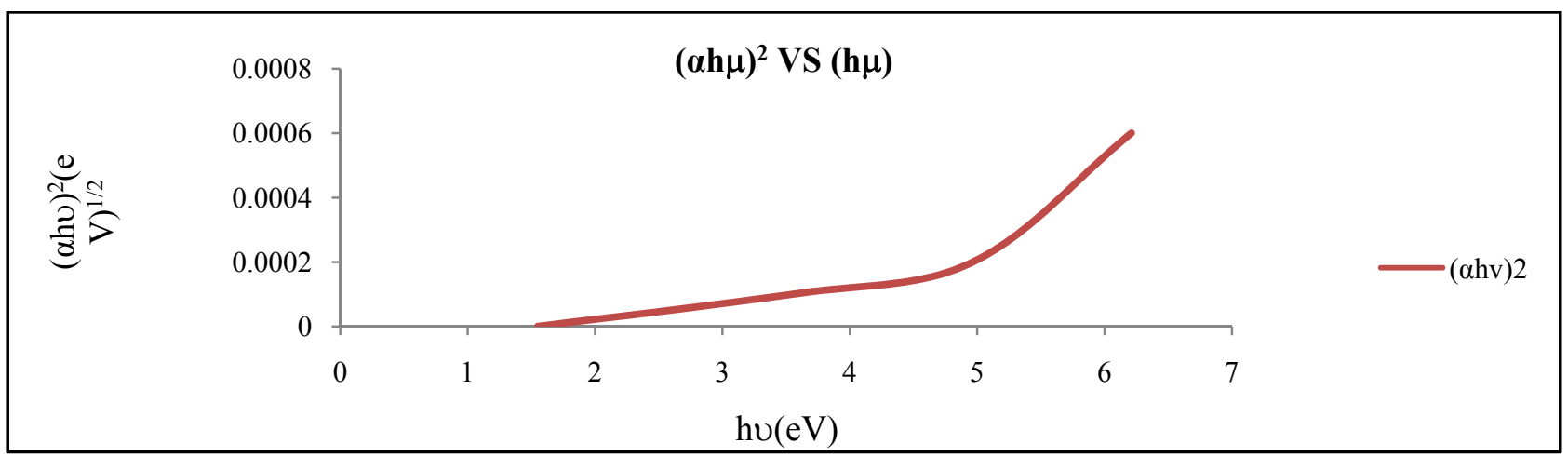

Fig. 13 The plot for band-gap energy $\left(E_{\text {bg }}\right)$ of $\mathrm{Cu}-\mathrm{ZnO}$.

Table 4 The maximum current $\left(I_{m}\right)$, maximum voltage $\left(V_{m}\right)$, short circuit current $\left(I_{\mathrm{sc}}\right)$ and open circuit voltage $\left(V_{\text {oc }}\right)$ of $\mathrm{Cu}-\mathrm{ZnO} / \mathrm{Si}$ film.

\begin{tabular}{lllll}
\hline Annealed temperature & $I_{\mathrm{m}}$ & $V_{\mathrm{m}}$ & $I_{\mathrm{sc}}$ & $V_{\mathrm{oc}}$ \\
\hline $400{ }^{\circ} \mathrm{C}$ & $3 \mu \mathrm{A}$ & $30 \mathrm{mV}$ & $4.08 \mu \mathrm{A}$ & $46.9 \mathrm{mV}$ \\
\hline
\end{tabular}

Table 5 The conversion efficiency $(\eta)$ and $\mathrm{FF}$ (fill factor) of $\mathrm{Cu}-\mathrm{ZnO} / \mathrm{Si}$ film.

\begin{tabular}{lll}
\hline Annealed temperature & $\eta(\%)$ & FF \\
\hline $400{ }^{\circ} \mathrm{C}$ & 0.063 & 0.47 \\
\hline
\end{tabular}

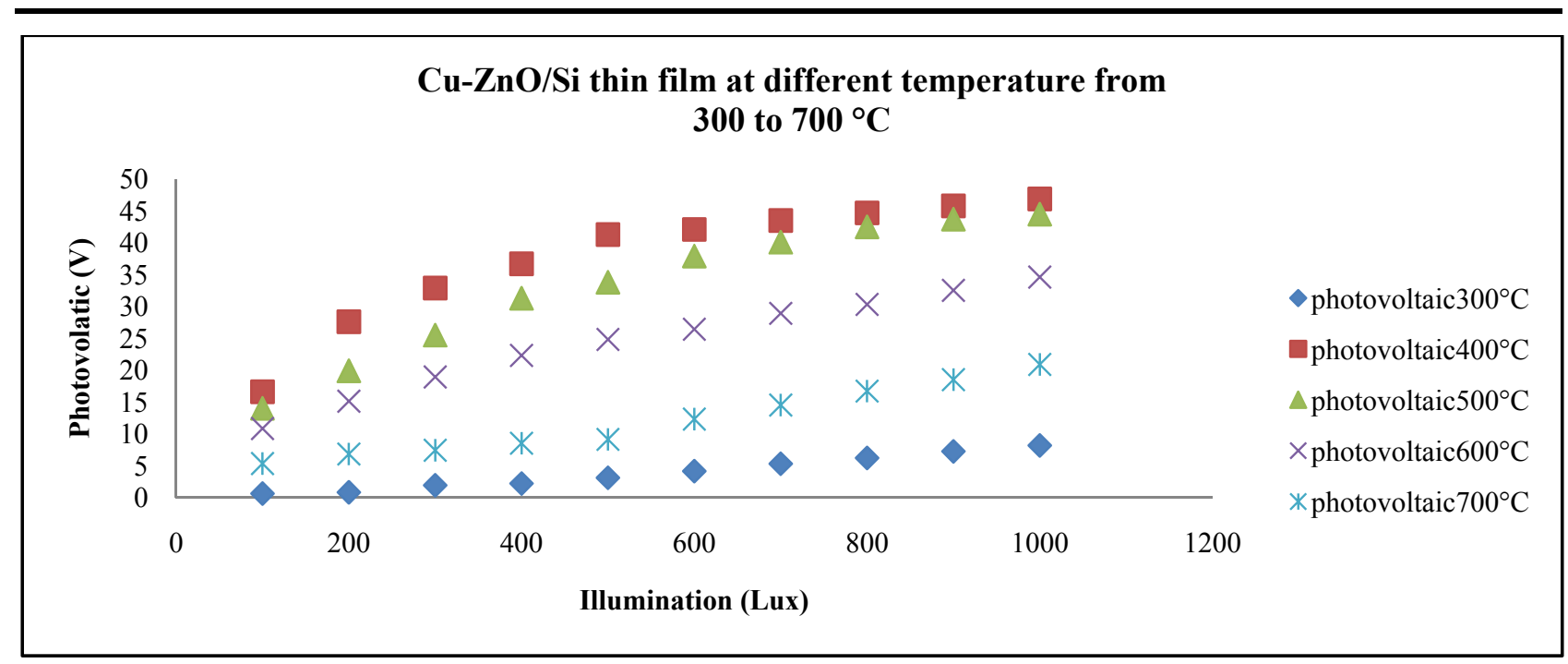

Fig. 14 Photovoltaic measurement of $\mathrm{Cu}-\mathrm{ZnO} / \mathrm{Si}$ film from 300 to $700{ }^{\circ} \mathrm{C}$. 


\section{Discussion}

Undoped $\mathrm{ZnO}$ and $\mathrm{Cu}$-doped $\mathrm{ZnO}$ were successfully synthesized by Co-precipitation process for three different doping ratios (such as 2, 3, $5 \mathrm{wt} \%$ ) and deposited on $\mathrm{p}$-Si substrate by screen printing method. $\mathrm{Zn}\left(\mathrm{NO}_{3}\right)_{2} \cdot 6 \mathrm{H}_{2} \mathrm{O}$ was used as a starting materials and $\mathrm{Cu}\left(\mathrm{NO}_{3}\right)_{2} \cdot 3 \mathrm{H}_{2} \mathrm{O}$ is used as a dopant material in this research. The synthesized undoped $\mathrm{ZnO}$ and $\mathrm{Cu}$-doped $\mathrm{ZnO}$ particles were found to be of single-crystal quality with hexagonal wurtzite structure. XRD measurements indicate that the synthesized $\mathrm{ZnO}$ crystals are in the hexagonal phase and dominant peaks are (100), (002) and (101). According to the SEM result, SEM images of $\mathrm{Cu}$-doped $\mathrm{ZnO}$ show hexagonal particles with random form. Doping ratio (3 wt \%) image shows clearly hexagonal structure but it has some holes, and can absorb moisture.

\section{Conclusion}

Cu-doped $\mathrm{ZnO}$ was synthesized by using co-precipitation method and $\mathrm{Cu}$-doped $\mathrm{ZnO}$ was successfully deposited on $p$-Si substrate by screen printing method. The microstructure and morphological properties of the $\mathrm{Cu}-\mathrm{ZnO}$ were investigated. The microstructure of $\mathrm{Cu}$-doped $\mathrm{ZnO}$ was examined by XRD. The XRD patterns showed that the $\mathrm{Cu}$-doped $\mathrm{ZnO}$ was of hexagonal structure and that the prepared film has the dominant peak of (101) preferred orientation. Crystallite size of $\mathrm{Cu}$-doped $\mathrm{ZnO}$ thin film was changed on the different doping ratios (2, 3 and 5 wt \%). In XRD analysis, the dominant peak of $\mathrm{Cu}$-doped $\mathrm{ZnO}$ with doping ratio (3 wt \%) is higher than other samples. Surface morphology of $\mathrm{Cu}$-doped $\mathrm{ZnO}$ was checked by SEM. The SEM image showed that the Cu-doped $\mathrm{ZnO}$ exhibited a uniform surface morphology and hexagonal microstructure.

The microstructure of $\mathrm{Cu}-\mathrm{ZnO} / \mathrm{Si}$ films was checked by XRD. Crystallite size of $\mathrm{Cu}-\mathrm{ZnO} / \mathrm{Si}$ thin film was changed at the different deposition temperatures. From the XRD result, the dominant peak (101) of diffusion temperature $400{ }^{\circ} \mathrm{C}$ is higher than other films. Smallest grain size of $\mathrm{Cu}$-doped $\mathrm{ZnO} / \mathrm{Si}$ film has diffusion temperature of $400{ }^{\circ} \mathrm{C}$ shown by the XRD pattern. From XRD results, the lattice constant $c / a$ has been calculated for synthesis of pure $\mathrm{ZnO}$ and $\mathrm{Cu}-\mathrm{ZnO}$. With the doping concentration of $3 \mathrm{wt} \%$ the lattice constant $a$ increases from 3.2480 $\AA$ to $3.2538 \AA$ and $c$ decreases from $5.2138 \AA$ to $5.1892 \AA$. XRD results show $\mathrm{Cu}$ is successfully doped into $\mathrm{ZnO}$ in $3 \mathrm{wt} \%$ samples and in other samples were $\mathrm{Cu}$ was not completely doped into $\mathrm{ZnO}$.

According to the UV-vis spectroscopy, bandgap energy of $\mathrm{Cu}$-doped $\mathrm{ZnO}$ doping ratio 3 wt \% was narrower than undoped $\mathrm{ZnO}$ and other doping ratios ( 2 and $5 \mathrm{wt} \%$ ). It can cause better electron mobility than other doping ratios. Bangap energy of $\mathrm{Cu}$-doped $\mathrm{ZnO}$ depends on $\mathrm{Cu}$ concentration. According to the $\mathrm{I}-\mathrm{V}$ characteristic measurement results $\mathrm{Cu}$-doped $\mathrm{ZnO} / \mathrm{Si}$ device shows solar cell behavior and it can be used for solar cell materials.

\section{Acknowledgements}

Authors deeply thank Professor Dr. Pho Kaung, Rector of University of Yangon for suggestion of this research work. We would like to thank Professor Dr. Khin Khin Win, Head of Department of Physics, University of Yangon, for valuable advices on our research.

\section{References}

[1] Bahsi, Z., and Oral, A. 2007. "Effect of Mn and Cu Doping on the Microstructures and Optical Properties of Sol-Gel Derived ZnO Thin Films.” Optical Materials 29 (6): 672-8.

[2] Ullah, R., and Dutta, J. 2008. "Photocatalytic Degradation of Organic Dyes with Manganess-Doped ZnO Nanoparticles.” Journal of Hazardous Materials 156 (1-3): 194-200.

[3] Fu, M., Li, Y., Wu, S., Lu, P., Liu, J., and Dong, F. 2011. "Sol-Gel Preparation and Enhanced Photocatalytic Performance of $\mathrm{Cu}$ Doped $\mathrm{ZnO}$ Nanoparticles." Applied Surface Science 258 (4): 1587-91. 
[4] Rekha, K., Nirmala, M., Nair, M., and Anukalini, A. 2010. "Structural, Optical, Photocatalytic and Antibacterial Activity of Zinc Oxide and Manganese Doped Zinc Oxide Nanoparticles.” Physica B 405 (15): 3180-5.

[5] Xu, C., Cao, L., Su, G., Liu, W., Liu, H., Yu, Y., and Qu, X. 2010. "Preparation of $\mathrm{ZnO} / \mathrm{Cu}_{2} \mathrm{O}$ Compound Photocatalyst and Application in Treating Organic Dyes."
Journal of Hazardous Materials 176 (1-3): 807-13.

[6] Liu, Z. L., Deng, J. L., Deng, J. J., and Li, F. F. 2008. "Fabrication and Photocatalysis of $\mathrm{CuO} / \mathrm{ZnO}$ Nano-composite via a New Method." Materials Science and Engineering B 150 (2): 99-104.

[7] https://www.researchgate.net/publication/321017142. UV/VIS Spectrophotometry-Fundamentals and Applications. 